\title{
Formação discursiva e autoria na produção \\ e na circulação de arquivos
}

Solange Mittmann ${ }^{l}$

\begin{abstract}
I discuss archive from two points of view in this article: the first one considering the meanings which are already-there, as an already-known object, composed whether of physical material or bits, and then as a theoretical and methodological notion based on Derrida, Foucault and Pêcheux. As an object, I discuss it based on its presence in the everyday life, emphasizing issues which are imposed by the advent of cyberspace. As a notion, I relate it with two other notions: discursive formation and authorship. In order to illustrate the discussion, I present three contemporary artworks by Erik Kessels, Eva and Franco Mattes, and Hasan Elali. The aim is to observe the way the authorship works in the construction and in the movement of the archive, as a slip or a displacement in relation to the discursive formation.

Keywords: archive; authorship; discursive formation; cyberspace.
\end{abstract}

Resumo: Neste artigo, discuto arquivo sob dois olhares: primeiramente, sob sentidos já-lá, como objeto já-conhecido, seja ele composto de matéria física ou de bits; a seguir, como noção teórico-metodológica, a partir de Derrida, Foucault e Pêcheux. Como objeto, discuto-o em sua presença no cotidiano, ressaltando questões que se impõem pelo advento do ciberespaço. Como noção, coloco-o em relação com outras duas noções: a de formação discursiva e a de autoria. A fim de ilustrar a discussão, cito três obras artísticas contemporâneas - de Erik Kessels, de Eva e Franco Mattes, e de Hasan Elali. O objetivo é observar o funcionamento da autoria na construção e no movimento do arquivo em relação à formação discursiva.

Palavras-chave: arquivo; autoria; formação discursiva; ciberespaço.

Introdução

A noção de arquivo tem sido acionada com frequência no âmbito da Análise do Discurso, sobretudo nas discussões sobre as novas tecnologias. O incômodo diante da potencialização da produção e circulação de textos na sociedade em rede (além da ruptura de limites antes tão definidos e acatados) tem motivado debates que, se em uma direção, convocam os analistas do discurso a trazerem seu aporte teórico-metodológico para a interpretação desse acontecimento histórico, por outra, instigam os analistas a pensarem algumas questões teóricas. E é uma noção que se mostra produtiva na medida em que provoca abordagens a respeito do contato solidário entre elementos pares, da circulação de objetos dentro de um arquivo ou de um arquivo para outro, das delimitações de fronteiras e das relações em rede com outros arquivos.

1 Doutora em Letras. Professora do PPG-Letras da UFRGS. Membro do Grupo de Estudos e Pesquisas em Análise do Discurso - GEPAD-RS. 
Neste artigo, proponho acionar, inicialmente, arquivo como objeto já-conhecido, seja ele composto de matéria física ou de bits, para em seguida abordá-lo como noção teórico-metodológica, a partir de Derrida (2001), Foucault (2002) e Pêcheux (1997). Na primeira perspectiva, embora trazendo diversos exemplos de arquivos de matéria física, o foco é o ciberespaço, considerados aí os suportes, a internet, mas também os internautas, as condições de produção, os discursos e suas formas de circulação. Na segunda, coloco-o em relação com outras duas noções: a de formação discursiva - em Foucault (2002) e em Pêcheux (1995) - e a de autoria - a função-autor de Foucault (1992) e a distinção entre função-autor e efeito autor conforme Gallo (2008).

\section{Arquivos sob o efeito de evidência}

Alguns arquivos estão presentes em nosso cotidiano como algo já-lá, já conhecido, e sobre eles lançamos gestos já esperados de busca, leitura, seleção, organização etc. É o caso de arquivos domésticos (de fotos, telefones, receitas, objetos colecionados, contas pagas), de trabalho (bibliografias, cadastros, planilhas) ou sociais/institucionais (videotecas, museus, locadoras). Para uma reforma na casa, buscamos a planta hidráulica num órgão municipal; para o traçado da árvore genealógica, recorremos aos arquivos de cartórios e igrejas; para a compra de um carro, ao arquivo de infrações. Percorrendo arquivos oficiais - tantos deles hoje disponíveis na internet - descobrimos um pouco de nós à disposição de qualquer interessado: lá estamos expostos, com nossos números de registro e catalogação, e informações de nossa vida que julgávamos privadas. A um gesto, qualquer internauta pode ter acesso ao nosso endereço, CPF, multas de trânsito, local de trabalho, amigos comuns nas redes sociais, pesquisas, publicações... Na rede de arquivos que constui a internet, um pouco de nossa vida está à disposição de qualquer interessado.

De aço ou madeira, com divisões em pastas e gavetas - essa imagem visual que temos de arquivo é tão presente na memória, que forma os ícones na tela do computador para representar "abrir" (resgatar, sacar) um documento já arquivado, ou "salvar" (guardar, arquivar) em uma pasta de cd, dvd, pen drive, cartão de memória etc. Em nossa lida com os excessos e com a possibilidade de perda, o arquivo digital e o arquivo impresso competem constantemente pelo maior espaço de armazenamento no menor espaço no ambiente. E, ainda, temos o chamado arquivo morto, com a função de guardar o que já não circula, não se utiliza, mas que ainda pode significar na eventualidade de ser buscado, ou seja, traz em si a virtualidade do ressuscitar. Como naquela historinha do estagiário que sugeriu ao chefe se desfazer do arquivo morto, digitalizando todos os documentos, e o chefe aceitou, desde que antes, o estagiário "xerocasse" tudo. A anedota revela que o arquivo está ligado ao receio de perder - mesmo que os documentos estejam esquecidos. Já nos museus e acervos, o arquivo tem sua existência pela necessidade de manter a memória "viva", para que não se esqueça a história.

Há ainda um outro aspecto sobre alguns arquivos que cabe trazer, que é o desejo de acumulação de um (im)possível no formato de um todo. É o caso das enciclopédias. Recentemente, deparei com uma Enciclopédia da História Universal, que trazia na capa personagens históricos, como Gandhi, Einstein e Madre Teresa. E fiquei a me perguntar quão pequeno é preciso ser o recorte de uma história universal para caber em uma enciclopédia, e quanto é preciso esquecer (interditar) dessa história para que se ouse fazer uma enciclopédia com tal título. 
Esse impasse sobre o que pode/deve entrar e o que deve ficar de fora já estava presente nos arquivos renascentistas descritos por Chartier (2007, p.2), cujos editores procuravam "fazer ready-mades de lugares comuns, ou seja, reunir de maneira impressa tudo o que se necessitava saber sobre um determinado tema". Tais arquivos tinham a função de servir como bancos de dados que alimentariam novos discursos. Ou, observando-se na via inversa, novos discursos deveriam sustentar-se, nutrir-se, constituir-se de discursos previamente selecionados, autorizados, legitimados e organizados em arquivo.

Assim, o enunciado descritivo de Chartier "tudo o que se necessitava saber sobre" nos serve para delinear uma série de ilusões não só dos bancos de dados do passado, mas também dos arquivos e arquivamentos atuais:

- Tudo: a ilusão de que os sujeitos dominam suas escolhas diante das ofertas desde sempre já-lá;

- o que: a ilusão de saber do que se fala e, ainda, de que o rechaçado não está presente;

- se: a ilusão de uma homogeneidade social, onde todos sofrem as mesmas determinações e da mesma forma;

- necessitava: a ilusão de naturalidade, de que as coisas e os fatos são como/porque são;

- saber: a ilusão de universalidade e transparência dos sentidos;

- sobre: a ilusão de que os limites estariam desde sempre estabelecidos.

"Tudo o que se necessitava saber sobre" seria, então, uma parte de um suposto "todo" (in)disponível, (im)possível de ser discursivizado, contido e apreendido. O que nos leva a perguntar: o que não se necessitaria ou não se deveria saber? Limites e formas de articulação do/no arquivo seriam determinados e impostos por quem? Talvez o permanente burlar dessas imposições seja umas das questões mais discutidas hoje quando se aborda o impacto do advento do ciberespaço na sociedade contemporânea. Afinal, os efeitos de naturalidade, transparência e universalidade são postos, frequentemente, em suspenso, diante dos movimentos dos internautas, a partir da formulação e circulação de novos discursos, antes não previstos.

A esse respeito, cabe trazer a distinção apontada por Orlandi $(2001$, p.9) entre os três momentos envolvidos nos processos de produção do discurso: a constituição, a formulação e a circulação. O primeiro se dá a partir da memória do dizer e está ligado ao eixo vertical da produção; o segundo é onde essa memória se atualiza, através do eixo horizontal. Quanto à circulação, importa, segundo a autora, considerar que “os 'meios' não são nunca neutros", cabendo-nos analisar, portanto, "como circulam (em que meios e de que maneira: escritos em uma faixa, sussurrados como boato, documento, carta, música etc.)”. (Ibid., p.11-12)

Sem dúvida, o modo de circulação faz significar de maneira particular os documentos de arquivo. E é importante ressaltar que os documentos de arquivo são tomados aqui como objetos discursivos, ou seja, em sua opacidade, constituídos na tensão das condições de produção ${ }^{2}$. É o que tentarei mostrar a partir das provocações que artistas contemporâneos têm efetuado quando discutem a circulação no ciberespaço. Para isso, cito brevemente - e não como corpus de análise, mas como gatilho para a discussão sobre arquivo - três obras que provocam discussões sobre a circulação de documentos e os movimentos de arquivo.

2 Por isso, documento, neste artigo, é considerado a partir de seu tratamento como monumento, isto é, não tomado isoladamente como comprovação da história, mas posto em relação, articulado, conforme Foucault (2002). 


\section{Arquivos em questão pela Arte}

O Museu do Futuro da Fotografia ${ }^{3}$, do holandês Erik Kessels, apresenta as postagens na internet como uma espécie de soterramento. A instalação foi montada em 2011 no Museu da Fotografia de Amsterdam e constitui-se de todas as fotos postadas no Flicrk ${ }^{4}$ durante um período de 24 horas. O resultado foram 6 milhões de fotos formando montanhas de papéis que ocuparam uma sala do museu. Ali se misturavam fotos públicas, privadas, sociais, individuais etc.

Pode-se dizer que foram postos em discussão na obra tanto o excesso como o acesso, dois fatores presentes entre nossas preocupações cotidianas a respeito do impacto da internet sobre a vida individual ou coletiva. O excesso é revelado e discutido quando os bits tomam forma de matéria física e tem-se certa dimensão do volume do arquivo da rede: um dia de produção de documentos imagéticos em bits e seu arquivamento em um site criado para essa finalidade corresponderia a uma sala física de museu lotada. E a tendência do volume, obviamente, é aumentar. Já no que se refere ao acesso, pode-se afirmar que quando as fotos são transportadas da internet para uma sala lotada de museu e recebem visitações, tem-se também certa dimensão do não-limite entre o público e o privado, assim como entre o individual e o coletivo, não só no novo local de acesso, mas na própria internet. Em resumo, a obra de Kessels constrói certa visualização de volume e de trânsito que é impactante, mas ainda é ínfima diante do volume e do trânsito presentes no ciberespaço.

A formulação e a circulação de documentos de arquivo também é o mote da obra de Eva e Franco Mattes, que em 1998, criaram o personagem Darko Maver ${ }^{5}$, um artista iugoslavo que produziria esculturas realistas de vítimas de assassinato em prédios abandonados e quartos de hotel. Eva e Franco Mattes tomaram fotos de notícias que circulavam na internet e apresentaram como se fossem imagens das esculturas do suposto artista. No ano seguinte, colocaram em ampla circulação uma foto da morte de Darko Maver, situando-a numa prisão durante um bombardeio da OTAN, e montaram uma seqüência de mostras póstumas. Depois das exposições e dos debates sucitados, os artistas, revelaram que Darko Maver era uma invenção.

A particular forma de circulação dos documentos fez com que fossem ressignificados. Num primeiro momento, documentos comprovadores de notícias diversas são tomados do âmbito do jornalismo e passam, então, a ser reunidos no âmbito da arte. Ou seja, cada documento já-situado em arquivos específicos (jornais) é deslocado para um arquivo novo e único (o conjunto de imagens) construído por Eva e Franco Mattes e recatalogado como um novo documento. No novo arquivo, os "novos" documentos são identificados como se viessem de uma mesma "fonte", a obra de Darko Maver. Neste primeiro momento, a reunião, na forma de arquivamento-catalogação de peças de uma obra, tornou os documentos instigadores de debate a partir da provocação da obra.

No momento posterior, depois de desfeita a farsa, os mesmos documentos (que já são outros, pois foram novamente ressignificados) passam a ser instigadores de um novo debate, agora sobre a própria construção ficcional daquele primeiro movimento de arquivamentocatalogação. Quer dizer, não é apenas o documento que é questionado (como comprovação

3 Uma notícia sobre a instalação pode ser encontrada em: http://www.bbc.co.uk/portuguese/noticias/2011/11/111116_fotos_exposicao_pu.shtml

4 www.flickr.com

5 A obra pode ser encontrada em: http://0100101110101101.org/home/darkomaver/index.html 
de uma verdade), mas a sua condição de documento em circulação, a interpretação que se efetua sobre ele a cada movimento. Afinal, como afirma Nunes (2007, p.374), "o material de arquivo está sujeito à interpretação e, mais do que isso, à confrontação entre diferentes formas de interpretação e, portanto, não corresponde a um espaço de 'comprovação', onde se suporia uma interpretação unívoca".

A discussão sobre/a partir da circulação de documentos de arquivo também é levantada pela obra de Hasan Elahi, que coloca em circulação na internet imagens de seu próprio cotidiano. Certa feita, o artista foi confundido com um terrorista pela CIA e, com receio de ser preso, começou a filmar e postar na internet seu cotidiano e sua localização. Criou o site Trânsito Rastreado ${ }^{6}$ (http://trackingtransience.net/), onde posta, com atualizações de hora em hora, um mapa indicando onde ele está (o artista anda sempre com um GPS) e as imagens que estão diante de si. Seu rosto não aparece, mas sim o que ele vê, o que faz, onde está, o que há no seu entorno etc.

Elahi joga com o movimento de arquivo de um cenário para outro: do espaço onde está seu corpo para o espaço da internet, e deste para os espaços de exposição em galerias. Cada um desses movimentos de arquivo faz com que os documentos (as imagens) e o próprio arquivo (o gesto de arquivamento) sejam ressignificados. Afinal, um prato sobre uma mesa não recebe os mesmos efeitos de sentido quando está diante do artista, diante da câmera, na tela do computador ao lado de um mapa, no telão de um museu de arte...

A descrição das três obras citadas acima permite notar que as mesmas questões são postas em discussão. Quem se depara com essas obras (e tantas mais que vêm discutindo os mesmos temas que envolvem o ciberespaço) é instigado a pensar sobre (des)limites diversos. $\mathrm{O}$ (des)limite entre o público e o privado é acionado como problema a discutir pelo fato de que tanto os visitantes da obra de Kessels como os da obra de Elahi em museus ou galerias tiveram acesso a documentos de arquivos da vida privada, da mesma forma que qualquer internauta ao acessar o Flicrk ou o site Trackingtransience. Já o (des)limite entre a vida vivida e a vida narrada é trazido à reflexão pelo recontar das histórias, quando uma foto entra em contato com outras em uma montanha de fotos, ou quando há um recorte da narrativa pela câmera e pelo GPS, ou através da construção do personagem fictício a partir de documentos de outras narrativas.

Também questionamentos são levantados a respeito do jogo excesso/falta, deriva/ contenção. $\mathrm{O}$ excesso de documentos (imagens) e de arquivos denunciaria uma tentativa insistente e provisória de desviar da falta constitutiva e permanente? O controle dos arquivos pela distribuição, exposição e acesso, seriam recursos igualmente insistentes e provisórios de conter a deriva? São questões que a arte tem lançado à sociedade sobre as relações que esta tem estabelecido com seus arquivos, principalmente os digitais.

\section{Três definições de arquivo}

Então, como diz Derrida (2001, p.11), não comecemos pelo arquivo, mas pela palavra arquivo: "Arkhê, lembremos, designa ao mesmo tempo o começo e o comando". Esses dois aspectos estão presentes em nossa reflexão: o arquivo como lugar de onde se parte, efeito de origem de outros discursos, e o arquivo como estabelecimento de diretrizes, normas para novos discursos. Mas, como afirmam Romão et al. (2010, p.124), "tais princípios parecem ser muitas vezes da ordem da ilusão, da impossibilidade”. Poderíamos dizer,

6 A notícia está em: http://obviousmag.org/archives/2012/02/hasan_elahi_-_o_foragido_que_todos_sabem_ onde_esta.html 


\section{Conexão Letras}

ainda, que se trata de um desejo e de um efeito de origem e de comando calcados sobre a própria impossibilidade de resgate e de controle. Ou seja, porque não podem resgatar as origens nem ter pleno controle ou comando sobre os documentos e os sentidos, os sujeitos precisam contentar-se com as ilusões de que, sim, é possível.

A necessidade de controle sobre a ordem do discurso e do arquivo pode ser descrita a partir da definição de arquivo em Foucault (2002, p.149) como "a lei do que pode ser dito, o sistema que rege o aparecimento dos enunciados como acontecimentos singulares", ou ainda o que "diferencia os discursos em sua existência múltipla e os especifica em sua duração própria", fornecendo aos discursos "seus modos de aparecimento, suas formas de existência e de coexistência, seu sistema de acúmulo, de historicidade e de desaparecimento". Para chegar a essa definição, Foucault precisa negar, é claro, as perspectivas que apontamos quando tratamos do arquivo a partir do efeito de evidência: totalidade, memória, eventualidade de ressurreição etc.

Já Pêcheux (1997, p.56), ao abordar as leituras de arquivo (assinalando as científicas e as literárias), afirma que "há fortes razões para se pensar que os conflitos explícitos remetem em surdina a clivagens subterrâneas entre maneiras diferentes, ou mesmo, contraditórias, de ler o arquivo (entendido no sentido amplo de "campo de documentos pertinentes e disponíveis sobre uma questão')". O autor alerta para o fato de que a maneira de abordar a língua é que sustenta as maneiras de ler o arquivo. Por isso, no trabalho de leitura de arquivo, é preciso considerar a relação entre "língua como sistema sintático intrinsecamente passível de jogo, e a discursividade como inscrição de efeitos linguísticos materiais na história". (Ibid., p. 62)

Materialidade histórica e materialidade linguística e imagética (entre outras) constituem os documentos de arquivo. Por isso, ali encontramos o jogo de forças que ocorre tanto na borda, selecionando o que pode entrar e excluindo o que não pode, como na articulação interna através de desnivelamentos, sobreposições, mas também reacomodações. Por outro lado, o próprio arquivo traz em si os efeitos de estabilidade e de naturalização - efeitos ideológicos fundamentais.

\section{Arquivo e formação discursiva}

Quando Foucault traz o tema do arquivo, alerta que não está se referindo nem à soma de textos guardados em uma cultura, nem às instituições responsáveis pela guarda. Refere-se ao que regula o surgimento de discursos, a sua não aleatoriedade, ou seja, ao fato de que esses discursos "tenham aparecido graças a todo um jogo de relações que caracterizam particularmente o nível discursivo". (FOUCAULT, 2002, p.149) Daí a definição de arquivo como lei e como sistema de regência.

Assim é que o autor relaciona a noção de arquivo à de enunciado, não pelo que ele é, não é, ou poderia ser (no sentido de o que poderia estar substituindo), mas por sua particularidade. Ou ainda, a condição de sua raridade: "o princípio segundo o qual puderam aparecer os únicos conjuntos de significantes que foram enunciados". (Ibid, p. 138)

E a questão da raridade do enunciado e do seu isolamento em meio à dispersão faz com que a noção de arquivo se relacione também com a noção de formação discursiva, no sentido foucaultiano de uma dispersão/regularidade presente em um certo número de enunciados: "uma ordem, correlações, posições e funcionamentos, transformações". (Ibid., p. 43) Essa aproximação se deve ao fato de que a análise dos enunciados, a partir da perspectiva do arquivo, "situa-se, de fato, no nível do diz-se", não como opinião individual, 
nem imposição coletiva, nem de voz anônima, "mas como o conjunto das coisas ditas, as relações, as regularidades e as transformações que podem aí ser observadas". (Ibid., p.141)

Partindo desse princípio de que o arquivo funciona como lei que regula ou transforma o enunciado estabelecendo sua raridade, propomos aqui considerá-lo também na relação com uma outra perspectiva de formação discursiva, já não pela definição foucaultina, mas efetuando um movimento que permita pensar o papel da ideologia na sua constituição e no seu funcionamento. Para isso, acionamos a noção pêcheutiana de formação discursiva, já que nessa perspectiva teórica ela está diretamente relacionada à de formação ideológica, pois a formação discursiva é a própria forma de discursivização das determinações da formação ideológica: "as formações discursivas representam 'na linguagem' as formações ideológicas que lhes são correspondentes". (PÊCHEUX, 1995, p. 161) É a partir de uma relação de "intrincação" (expressão de Pêcheux) com a formação ideológica, que o autor define a formação discursiva como "o que determina o que pode e deve ser dito (articulado sob a forma de uma arenga, de um sermão, de um panfleto, de uma exposição, de um programa etc.)". (Ibid., p. 160)

Nesta mesma perspectiva, Romão et al. (2011, p.12) afirmam que o arquivo opera "na tensão entre o que pode e deve ser dito e o que pode e deve ser arquivado para circular em público ou para dele se esconder".

Assim, considerando-se tanto a determinação do que pode e deve ser dito, como a possibilidade de transformação (por exemplo, pela contra-identificação de uma posição-sujeito), pode-se pensar o arquivo no jogo de forças entre posições-sujeito de uma mesma formação discursiva ou entre formações discursivas, a partir da intervenção de uma memória ${ }^{7}$.

Voltando às três obras artísticas descritas acima, podemos observar a tensão presente/ proposta a partir dos movimentos dos documentos tomados de formações discursivas como a tecnológica, a jornalística, a da vida privada, a das redes sociais e apropriados pela formação discursiva artística para aí serem ressignificados. Afinal, é na formação discursiva que os documentos recebem sentidos, que passam a ser tomados como sempre-já-lá. Este movimento de atribuição de sentidos de uma formação discursiva para outra nos leva à questão da autoria.

\section{Arquivo e autoria}

Para esta reflexão, tomarei a noção de autoria a partir da formulação de Foucault (1992) sobre a função-autor e da distinção estabelecida por Gallo (2008) entre função-autor e efeito-autor. Esse percurso terá sempre presente a relação com a formação discursiva, na perspectiva pêcheutiana.

Para Foucault (Ibid., p.46), a função-autor é "característica do modo de existência, de circulação e de funcionamento de alguns discursos no interior de uma sociedade". E aqui me atenho particularmente à circulação, pois me permite pensar sobre o funcionamento da função-autor nos movimentos de arquivo. Para isso, retorno à provocação de Eva e Franco Mattes: quando alguns documentos de arquivo formulados e significados a partir da formação discursiva jornalística passam por um gesto de reapropriação e ressignificação a partir da formação discursiva artística, formando um novo arquivo, temos aí um gesto de autoria, que envolve recorte, movimento, reapropriação e ressignificação.

Considero que um movimento de ressignificação pode ocorrer de duas formas: pode ser caracterizado como um deslocamento de uma formação discursiva para outra, ou como

7 Remeto aqui a outro texto (MITTMANN, 2008), em que abordei proximidades e distâncias entre arquivo e memória. 
um deslizamento entre posições-sujeito no âmbito de uma mesma formação discursiva. Na obra de Eva e Franco Mattes, primeiramente há um deslocamento de documentos de arquivo da formação discursiva jornalística para a formação discursiva artística, onde esses objetos são ressignificados; a seguir, num novo movimento, ocorre um deslizamento de uma posição-sujeito para outra no âmbito da mesma formação discursiva artística, com uma nova ressignificação desses objetos.

Além disso, uma característica da função-autor, ainda segundo Foucault, é que pode dar lugar, simultaneamente, a "eus" diversos, ou seja, a diferentes posições-sujeito, abarcando a dispersão. E é o que acontece quando as fotos produzidas no âmbito do fotojornalismo policial são atribuídas à produção artística de Darko Maver. Posteriormente, quando desfeita a farsa, novamente, um gesto de autoria revela a dispersão: Darko Maver nunca existiu. Para, em seguida, circundar essa dispersão formando um novo efeito de unidade: Darko Maver é uma obra de Eva e Franco Mattes.

Considerando a diferença entre as concepções de formação discursiva (de Foucault, como busca de uma regularidade, e de Pêcheux, na relação com a formação ideológica) descrita acima, cabe trazer aqui a diferença entre as duas concepções de posição-sujeito. Para Foucault, a posição-sujeito é um lugar vazio que pode ser ocupado por qualquer indivíduo. Já na perspectiva dos analistas do discurso que seguem os preceitos de Pêcheux, a posição-sujeito é pensada a partir das relações identificação ou contra-identificação com uma formação discursiva (o que Pêcheux chama de tomada de posição), o que leva a concluir que a posição-sujeito é já ocupada pelos saberes de uma formação ideológica.

Como consequência, temos uma dispersão de posições-sujeito na obra de Eva e Franco Mattes, que trazem em si uma memória de saberes de diferentes formações discursivas: a formação discursiva jornalística e a formação discursiva tecnológica, onde os documentos receberam sentidos, e, finalmente, a formação discursiva artística, onde os documentos passam a constituir uma obra, sofrendo a determinação de sentidos a partir não só da apropriação (no primeiro movimento, o da construção da farsa), mas também da contestação de saberes daquelas outras duas (no segundo movimento, da revelação da farsa).

Gallo (2008, p.213) afirma que “'dispersão' e 'fechamento' convivem e se intercambiam todo o tempo, ambas produzindo seus efeitos (o efeito de 'fim' e o efeito de 'inacabado')" na prática da textualização. Com as análises das três obras artísticas, podemos afirmar que esses dois efeitos ocorrem na textualização das obras a partir da circulação de documentos de um arquivo para outro, através da formulação de novos arquivos e, mesmo, com o questionamento às leituras de arquivo, sempre sob a determinação da formação discursiva artística.

Mas há ainda uma outra noção trazida por Gallo que pode nos ajudar a ler os arquivos das três obras, bem como a ler as leituras de arquivo propostas/provocadas pelos artistas. Trata-se da noção de efeito-autor, que "diz respeito ao confronto de formações discursivas com nova dominante em um acontecimento discursivo". (Ibid., p.211) E a autora cita como exemplo "o evento discursivo que constitui a rede internet, que põe em confronto o discurso da mídia digital com incontáveis discursos dominantes, fazendo surgir daí novos efeitos de autoria". (Ibid., p.214)

Nas três obras analisadas, não encontramos, precisamente, o surgimento de uma nova formação discursiva. A formação discursiva tecnológica (com a internet) se apresenta como já-lá, bem como a formação discursiva artística. O contato das duas formações discursivas na forma de tensão, nessas três obras, não chega a caracterizar o surgimento de uma nova formação discursiva, nem mesmo de uma nova posição-sujeito, pois a ciberarte e arte digital também se apresentam como já-lá. O que temos com as obras é o questionamento, pelo discurso artítisco, à produção, circulação e leitura dos documentos dos arquivos tecnoló- 
gicos. Ou seja, o que ocorre é a apropriação e a ressignificação de documentos de arquivo já-significados por uma formação discursiva (seja ela a jornalística, a tecnológica, a da vida privada, das redes sociais etc.) por sujeitos identificados, cada um de forma particular, com outra formação discursiva (a artística), através da construção de novos arquivos.

Cabe, porém, destacar que a obra de Hasan Elahi, que é produzida a partir da posição-sujeito da arte digital, efetua movimentos que poderiam caracterizar um efeito-autor: o deslimite entre sua vida (um fragmento de narrativa ficcional, que, porém, se apresenta como se fosse uma realidade plena) e a obra digital, na medida em que o artista carrega consigo sempre a câmera e o GPS, alterando sua rotina a partir da obra, ficcionando-se e marcando deslimites de tempo e espaço da formulação, da enunciação, da circulação e do acesso. É como um gesto de constante retorno-tranformação na produção das imagens que compõem o arquivo. Embora a formação discursiva ainda seja a artística, não se trata apenas de apropriação e ressignificação a partir desta, mas de um impacto sobre o modo de relacionar-se com a formação discursiva tecnológica, o que parece caracterizar um efeito-autor.

\section{Considerações finais}

É com a conhecida afirmação de Pêcheux (1990, p.53) que inicio o encerramento desta reflexão: "Todo enunciado é intrinsecamente suscetível de tornar-se outro, diferente de si mesmo, se deslocar discursivamente de seu sentido para derivar para um outro..." Se os sentidos são considerados em sua deriva, e os documentos são tomados como monumentos, em sua opacidade, não poderia ser diferente com o arquivo.

No recorte que aqui fiz, foi possível observar arquivos construídos, transformados ou reconstruídos por gestos de leitura, de recorte, de apropriação, de produção e de circulação de documentos a partir da identificação com uma formação discursiva. Tais gestos confirmam que os documentos não são elementos de comprovação de fatos - ao contrário: eles são tomados justamente para o questionamento dessa ilusão. São tratados, como diria Foucault, como monumentos. São tomados, na perspectiva pêcheuxtiana, em sua opacidade, no jogo de tensão e deriva entre posições-sujeito de uma formação discursiva e entre formações discursivas, o que produz o movimento de sentidos, seja na forma de deslizamento, seja na de deslocamento.

Tais gestos de autoria, sempre determinados pela identificação com uma formação discursiva, colocam em questionamento os modos de circulação de arquivo no ciberespaço presentes em nosso cotidiano. Trata-se de uma autoria que se apropria, ressignifica e coloca em nova circulação arquivos e documentos de arquivo que serão novamente ressignificados.

Diferentes processos podem ser identificados na leitura de arquivo: o da formulação, da enunciação, da circulação e do acesso. E quanto se trata de arquivos que circulam no ciberespaço e, ainda, de um questionamento sobre as formas de circulação nesse meio, esses processos são envolvidos em (im)precisões de tempo e espaço, em (des)limites de realidade e virtualidade, em derivas, direcionamentos e escapes.

\section{Referências}

CHARTIER, Roger. Entrevista a Carlos Alfieri. El País Cultural, año XVIII, n. 917, Montevideo, 01/06/2007, p.1-3.

DERRIDA, Jacques. Mal de arquivo: uma impressão freudiana. Rio de Janeiro: Relume Dumará, 2001. Trad. de Cláudia de Moraes Rego. 


\section{Conexão Letras}

FOUCAULT, Michel. A arqueologia do saber. 6.ed. Rio de Janeiro: Forense Universitária, 2002. Trad. de Luiz F.B. Neves.

. O que é um autor? In: O que é um autor? 3.ed. Portugal: Vega, 1992. p.29-87.

Trad. de Antonio Fernandes Cascais e Eduardo Cordeiro.

GALLO, Solange Leda. Autoria: função do sujeito e efeito do discurso. In: TASSO, Ismara. Estudos do texto e do discurso: interfaces entre língua(gens), identidade e memória. São Carlos: Claraluz, 2008.

MITTMANN, Solange. Redes e ressignificações no ciberespaço. In: ROMÃO, Lucília de Souza, GASPAR, Nádea. (Orgs.). Discurso midiático: sentidos de memória e arquivo. São Carlos: Pedro e João, 2008, v. , p. 113-130.

NUNES, José Horta. Leitura de arquivo: historicidade e compreensão. In: INDURSKY, F.; LEANDRO FERREIRA, M.C. (Orgs.) Análise do Discurso no Brasil: mapeando conceitos, confrontando limites. São Carlos: Claraluz, 2007.

ORLANDI, Eni P. Discurso e texto: formulação e circulação dos sentidos. Campinas: Pontes, 2001.

PÊCHEUX, Michel. Semântica e discurso: uma crítica à afirmação do óbvio. 2.ed. Campinas: Unicamp, 1995. Trad. de Eni P. Orlandi et al.

. Ler o arquivo hoje. In: ORLANDI, Eni P.(org.) Gestos de leitura: da história no discurso. 2.ed. Campinas: Unicamp, 1997. p.55-66. Trad. de Maria das Graças do Amaral. Orlandi.

. O discurso: estrutura ou acontecimento. Campinas: Pontes, 1990. Trad. de Eni P.

ROMÃO, Lucília M. S.; GALLI, Fernanda C.S.; PATTI, Ane R. Arquivo em cena: “impressões" de leitura sobre o tema. Desenredo, Passo Fundo, v.6, n.1, p. 123-134, jan./jun 2010.

ROMÃO, Lucília M. S.; LEANDRO FERREIRA, Maria Cristina; DELA SILVA, Silmara. Arquivo. In: MARIANI, Bethania [et al.] Discurso, arquivo e... Rio de Janeiro: 7 Letras, 2011. 